\title{
Produção de vulnerabilidades em saúde: o trabalho das mulheres em empresas agrícolas da Chapada do Apodi, Ceará
}

\author{
Production of health vulnerabilities: women's work in agricultural \\ companies of Chapada do Apodi, Ceará
}

Mayara Melo Rocha', Raquel Maria Rigotto²

RESUMO O estudo analisa os impactos que o trabalho nas empresas de fruticultura irrigada, instaladas na região da Chapada do Apodi, Ceará, exerce sobre a saúde das mulheres. Trata-se de uma pesquisa qualitativa realizada, de 2014 a 2015, por meio de trabalho de campo de base etnográfica, entrevistas semiestruturadas e observação do processo de trabalho. Os dados foram analisados pelo referencial da Análise do Discurso. Verificou-se que a organização do trabalho nessas empresas é marcada por uma forte divisão sexual; observa-se que, sobre as mulheres, recaem riscos específicos e violações de direitos que promovem vulnerabilidades e repercutem negativamente sobre suas condições de saúde.

PALAVRAS-CHAVE Saúde do trabalhador. Trabalho feminino. Agronegócio.

\begin{abstract}
The study analyzes the impacts that the work at the irrigated fruit companies, installed at Chapada do Apodi, Ceará, exerts on women's health. This is a qualitative research developed between the years 2014 and 2015, through ethnographic work, semi-structured interviews and observation of the work process. Data were analyzed through Discourse Analysis. It was observed that the organization of work in those companies is characterized by a great sexual division. It has been found that women are threatened by specific risks and violations of rights that promote vulnerabilities and impact their health conditions.
\end{abstract}

KEYWORDS Occupational health. Women, working. Agribusiness.

1 Universidade Federal do Ceará (UFC), Núcleo Tramas: Trabalho, Meio Ambiente e Saúde Fortaleza (CE), Brasil. mayaramelorocha@gmail. com

2 Universidade Federal do Ceará (UFC),

Departamento de Saúde Comunitária e Núcleo

Tramas: Trabalho, Meio Ambiente e Saúde (UFC) Fortaleza (CE), Brasil. raquelrigotto@gmail.com 


\section{Introdução}

Este artigo analisa os impactos que o trabalho nas empresas de fruticultura irrigada, instaladas na Chapada do Apodi, localizada no Baixo Jaguaribe, Ceará, exerce sobre a saúde das mulheres. Os resultados expostos representam um recorte decorrente do 'Estudo sobre exposição e impactos dos agrotóxicos na saúde das mulheres camponesas da região do Baixo Jaguaribe, Ceará', realizado entre 2013 e 2015.

Ao se considerar as desigualdades das relações de gênero, investigam-se as formas pelas quais a organização, a divisão sexual e a precarização do trabalho na cadeia produtiva do agronegócio vulnerabilizam a saúde das trabalhadoras. $\mathrm{O}$ avanço da modernização agrícola induz processos de vulnerabilização (PORTO; ROCHA; FINAMORE, 2014) ao impactar os distintos ecossistemas e alterar os modos de acesso à terra e à água, bases do modo de viver e produzir das populações camponesas. De acordo com Porto (2012), o modelo produtivo, pautado pela exportação de commodities rurais e pela exploração intensa de recursos naturais, sustenta-se por meio da produção de externalidades negativas materializadas "em destruições e prejuízos sociais, ambientais, culturais e à saúde pública" (PORTO, 2012, P. 39). Essas externalidades repercutem principalmente sobre os sistemas públicos de saúde e seguridade social e sobre as populações mais vulnerabilizadas que passam a sofrer inúmeras violações de direitos (PORTO, 2012).

A modernização agrícola também tem impulsionado a reconfiguração das relações de trabalho ao promover, por meio de processos de proletarização, a inclusão subordinada de camponeses e camponesas. Para Thomaz Júnior (2001), a modernização dos processos produtivos na agricultura se assenta sobre o avanço das técnicas capitalistas de dominação do trabalho pelo capital. Nesse contexto, alteram-se as relações sociais de produção e de trabalho e reconfiguram-se os territórios camponeses enquanto espaços tecnificados e incorporados aos mercados globais. Segundo Rigotto et al. (2013), a reorganização produtiva nesses territórios pode ser fonte de exploração, adoecimento, mutilação e morte, fatores que dependem diretamente das condições e organização do trabalho. Para Harvey (1992), a organização da produção e do trabalho no contexto da acumulação flexível do capital se caracteriza pela heterogeneidade tecnológica, combinando elementos de sistemas de produção e formas de dominação e controle do trabalho. Ao analisar a ocupação das mulheres em empresas agrícolas na região do Baixo Jaguaribe, estado do Ceará, Bezerra e Elias (2005) observaram que o agronegócio ampliou a divisão social e sexual do trabalho, coadunando com as observações de Lastarria-Cornhiel (2008) ao analisar a inserção das mulheres na cadeia produtiva do agronegócio em diversos países latino-americanos. Segundo Lastarria-Cornhiel (2008), a organização do trabalho é marcada por uma forte divisão sexual que destina às mulheres os trabalhos menos qualificados. Além disso, elas recebem as menores remunerações e ocupam o maior número de empregos temporários, fato também verificado no Ceará por Bezerra e Elias (2005). Desse modo, observa-se que a análise dos impactos da reestruturação produtiva sobre o trabalho e a saúde das mulheres da Chapada do Apodi demanda uma maior compreensão sobre a inserção delas na cadeia produtiva do agronegócio. Assim, busca-se desvelar os processos envolvidos na vulnerabilização das trabalhadoras do agronegócio relacionando as categorias de gênero, trabalho e saúde com as reflexões oriundas da realidade encontrada, ou seja, condições de trabalho marcadas pela precariedade e informalidade, pela exposição a riscos, por extensas jornadas de trabalho, por pressão pelo alcance de metas de produtividade e por baixos salários repercutindo negativamente sobre a saúde das trabalhadoras. 


\section{Metodologia}

A pesquisa possui uma abordagem qualitativa (MINAYO, 2013) considerando que a contextualização das estruturas sociais e a historicidade dos fenômenos são fundamentais para a análise. Para tanto, realizou-se um trabalho de campo de base etnográfica, de julho de 2014 a fevereiro de 2015, por meio da observação participante (FERNANDES; MOREIRA, 2013) desenvolvida nos momentos coletivos da comunidade como reuniões, festejos, romarias, entre outros, e também por meio conversas informais realizadas com os sujeitos da pesquisa. Em todas as etapas do processo, o diário de campo e os registros fotográficos foram utilizados.

Foram realizados estudos in locu do processo de trabalho nas empresas selecionadas por meio de visitas previamente agendadas nas quais se realizaram a observação direta e a coleta de informações com técnicos das empresas, orientadas por roteiro que abordava as relações de trabalho, o fluxograma da produção, a organização do trabalho, os postos de trabalho/ funções, a identificação de riscos ocupacionais e das medidas de controle adotadas, bem como as atividades do Serviço Especializado em Segurança e Medicina do Trabalho (PIGNATI; MACIEL; RIGOTTO, 2013). Os estudos do processo de trabalho desenvolveram-se em duas empresas transnacionais do ramo da fruticultura: uma delas produtora de banana, que será chamada de 'empresa X', e a outra produtora de melão, que será nomeada como 'empresa Y'. A seleção dessas empresas considerou a representatividade que possuem, pois, juntas, empregam mais da metade das mulheres as quais se teve acesso durante a pesquisa de campo. A empresa $\mathrm{X}$ empregava 60 mulheres entre seus 340 funcionários, e a empresa Y empregava 74 mulheres entre seus 528 funcionários. Finalmente, trabalhou-se com entrevistas que se mostraram a forma de coleta de dados mais adequada para o segmento de mulheres empregadas na fruticultura, uma vez que a carga horária de trabalho limita a participação delas em encontros ou oficinas de grupo, e foram realizadas com 11 mulheres. As entrevistadas possuíam entre 26 e 52 anos, todas tinham filhos e apresentavam um baixo grau de escolaridade. Em relação ao estado civil, 9 eram casadas ou viviam em união estável, 1 era solteira e 1 separada. Em relação à ocupação, 4 estavam empregadas na empresa Y, 3 na empresa $\mathrm{X}$ - entre elas, uma estava afastada do trabalho por doença ocupacional -; 2 haviam sido demitidas da empresa $\mathrm{X}$ - uma delas portadora de doença ocupacional -; e, finalmente, 2 trabalhavam em outras empresas de menor porte. Do universo pesquisado, 3 mulheres trabalhavam no campo, 1 com lavagem de Equipamentos de Proteção Individual (EPI) e as outras 7 na packing house. $\mathrm{O}$ roteiro de entrevista semiestruturado foi composto por questões que objetivaram conhecer a rotina e a organização da jornada de trabalho das mulheres, os riscos à saúde e os processos de vulnerabilização aos quais estão expostas. As entrevistas foram transcritas respeitando as expressões características das falas para não alterar entonações ou realizar correções, exceto aquelas que pudessem dificultar a compreensão do enunciado, constituindo o corpus da análise que foi realizada a partir do referencial da Análise do Discurso (IÑIGUEZ, 2004).

A pesquisa foi submetida ao Comitê de Ética em Pesquisa da Universidade Federal do Ceará e foi aprovada por meio do Parecer 906.270 - 2014. Todas as entrevistadas assinaram o Termo de Consentimento Livre e Esclarecido. Os nomes utilizados para identificá-las neste artigo são fictícios e foram escolhidos pelas próprias mulheres de modo a proteger suas identidades. 


\section{Resultados}

\section{O trabalho das mulheres nas empre- sas agrícolas da Chapada do Apodi (CE)}

Observou-se que uma forte divisão sexual marca a organização do trabalho nas empresas agrícolas pesquisadas. Verificouse que o setor denominado packing house é composto majoritariamente por mulheres e alguns poucos homens em cargos de supervisão, os chamados 'encarregados'.

Apresenta-se o fluxograma do processo de trabalho da produção de banana na empresa $\mathrm{X}$ para evidenciar a divisão da alocação de homens e mulheres (figura 1).

Figura 1. Fluxograma da produção de banana na empresa $X$
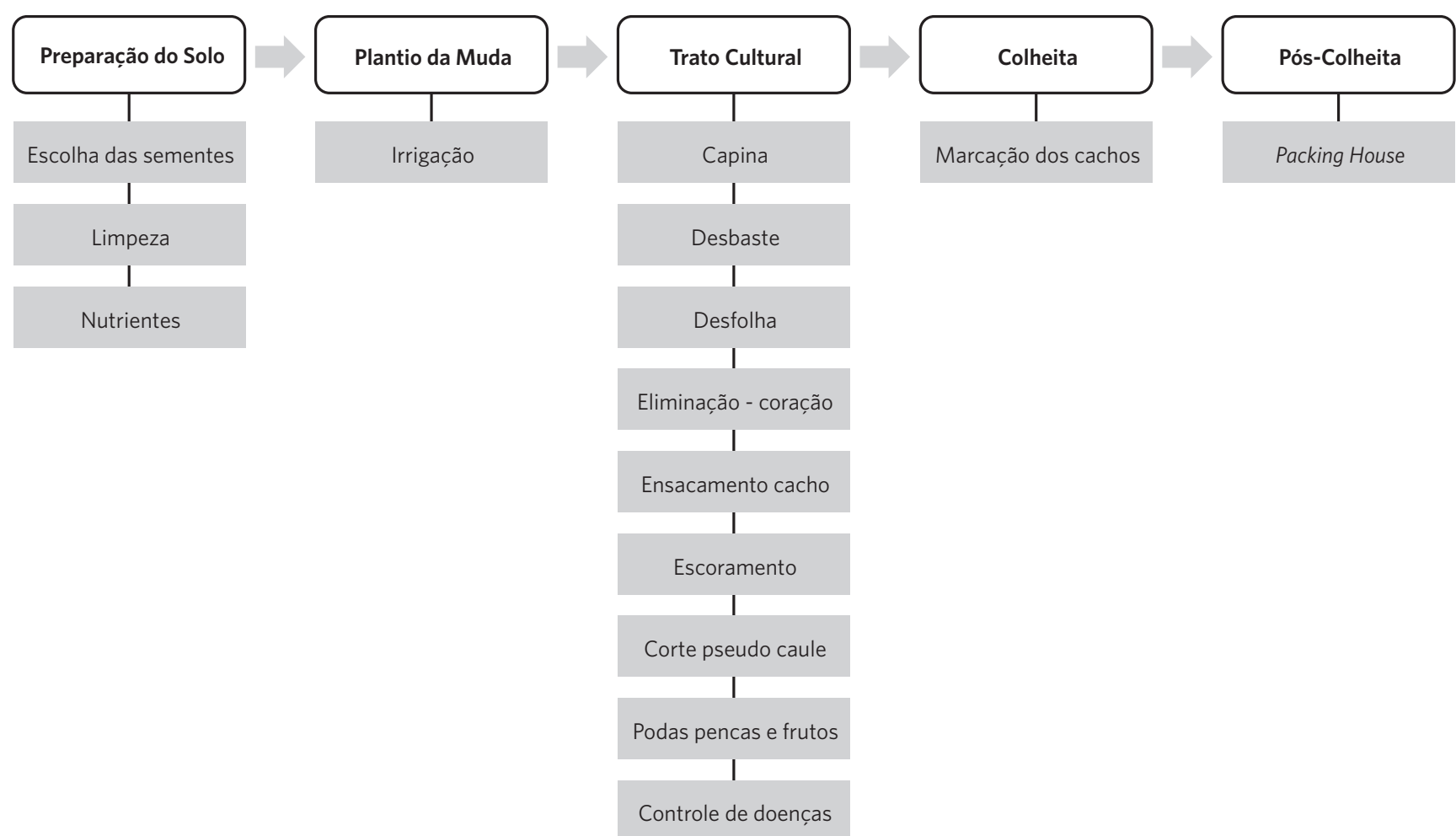

Fonte: Castro e Braga (2011), reorganizado pelas autoras.

Todas as etapas realizadas no campo, anteriores à pós-colheita, são executadas por homens. As mulheres concentram-se nas atividades relacionadas com a última fase do processo, no interior da packing house - um galpão no qual as frutas, movidas por meio de esteiras rolantes, passam por processos que vão da lavagem ao empacotamento, conforme apresenta e descreve o diagrama (figura 2). 
Figura 2. Organização do trabalho das mulheres no setor packing house da empresa X
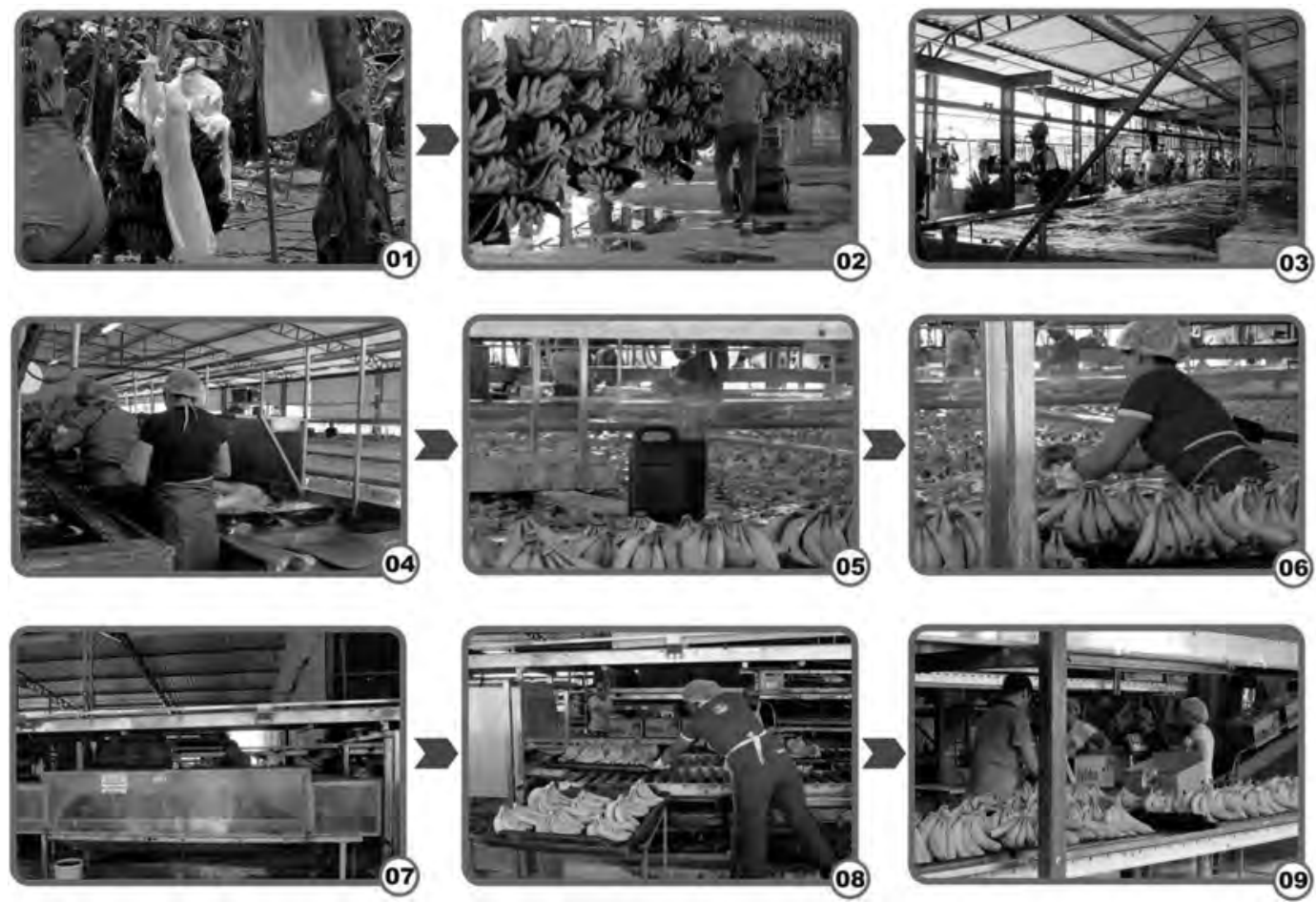

Fonte: Elaboração própria.

Descrição das etapas expostas na figura 2.

1 - Os frutos colhidos, ainda cobertos com sacos de propietileno e protegidos por esponjas, são transportados em cabos aéreos até a packing house.

2 - Depois dos sacos serem retirados e passarem por uma primeira ducha de limpeza, os frutos chegam ao galpão onde são retiradas as esponjas de proteção.

3 - É realizada a primeira lavagem num tanque com solução de sulfato de alumínio mais fungicida para desinfecção de fungos trazidos do campo.

4 - É realizada a 'seleção' dos frutos para separar aqueles que atingem o controle de qualidade exigido pelo mercado externo. Essa função é desempenhada basicamente por mulheres e exige muita concentração, movimentos repetitivos e ágeis, além de habilidade para manusear objetos cortantes.

5 - Os frutos são imersos em um tanque com cloro.

6 - Passam para o setor de bandejamento onde também há predominância de mulheres que, ao ritmo da esteira, precisam organizar os frutos em bandejas. A função exige muita concentração e agilidade.

7 - Os frutos passam por uma máquina na qual recebem aspersão de fungicidas.

8 - Os frutos passam pela 'selagem', fase na qual recebem etiquetas das empresas exportadoras.

9 - Finalmente, os frutos passam para a fase final de embalagem. Nessa fase, as mulheres realizam o trabalho de conferência do 
peso das caixas enquanto os homens realizam o empacotamento e o empilhamento.

Conforme visualizou-se, quase todas as funções da packing house são exercidas por mulheres, com exceção daquelas que exigem o uso de força física, a exemplo do empacotamento e empilhamento.

Em relação à empresa $\mathrm{Y}$, voltada para a produção de melão, verificou-se que também existe divisão sexual do trabalho na packing house; no entanto, há mulheres trabalhando no campo, principalmente no plantio de mudas. Essa diferença possivelmente ocorre pela especificidade do plantio de melão, que exige procedimentos cuidadosos e delicados - habilidades geralmente atribuídas às mulheres. Além disso, a packing house da empresa Y possui um processo mais mecanizado de modo que sobram poucas funções para as mulheres. No entanto, a divisão sexual do trabalho na empresa Y também é evidente, pois as mulheres ficam restritas às funções que exigem maior concentração e velocidade: a limpeza, a etiquetagem dos frutos e o pincelamento (aplicação de fungicida). Observa-se que as atividades prescritas para as mulheres nas duas empresas estudadas são restritas, sendo que algumas atividades são executadas exclusivamente por mulheres. A seleção das frutas é um exemplo disso, conforme explicita Gezabel:

O nosso [trabalho] de seletora, só mulher faz. Não sei [a razão], mas é só mulher, tanto faz ser na Empresa $X$ como na Empresa $L$ [outra transnacional instalada na região]. Pode ir entrevistar na Empresa L que é do mesmo jeito. Não entra homem na seleção.

A função citada por Gezabel é provavelmente destinada às mulheres por exigir habilidades que são associadas ao universo feminino, ou seja, paciência, concentração, destreza e precisão dos movimentos. Durante o estudo na empresa $X$, perguntou-se à técnica em segurança do trabalho qual a razão das mulheres assumirem majoritariamente essa função, e assim foi respondido "É que as mulheres são mais cuidadosas". Marcondes et al. (2003) analisam que se projeta sobre as mulheres a imagem da dona de casa e associam-se a elas supostas habilidades 'naturais' femininas. Habilidades que foram aprendidas pelas mulheres na esfera do trabalho reprodutivo e que, embora sejam amplamente aproveitadas pelas empresas, não são equiparadas àquelas adquiridas em formações e treinamentos formais. Além disso, esse estatuto de 'habilidade natural' acaba por desqualificar os postos de trabalho das mulheres, pois, como seus conhecimentos são compreendidos como espontâneos, não possuem valor agregado. Assim, as qualificações femininas são invisibilizadas e, mesmo que sejam reconhecidas como necessárias ao processo de produção, não resultam em melhores salários. Soares (1997) salienta que a desqualificação do trabalho das mulheres aprofunda a segregação dos postos de trabalho e a depreciação daqueles assumidos por mulheres que, em geral, são os mais mal remunerados e com as piores condições de execução.

A invisibilidade das qualificações femininas resulta no que Britto (1999) nomeia de prescrição naturalizada do trabalho. Um processo que corresponde à divisão naturalizada do trabalho entre homens e mulheres e se materializa na organização específica dos espaços de trabalho, equipamentos e máquinas que cada um irá utilizar. Com base em supostas qualidades universais das mulheres, como a capacidade de executar muitas tarefas ao mesmo tempo, de adaptação à monotonia e à realização de tarefas repetitivas, supõe-se que a assimilação do trabalho ocorre de forma espontânea e que as mulheres não precisam de espaços adaptados ou de treinamento específico para as funções que irão desempenhar. Assim, percebe-se que as mulheres empregadas nas empresas agrícolas estudadas podem ser mudadas de função diversas vezes, sem que recebam orientação para as novas tarefas - sempre no âmbito daquelas entendidas como mais simples e para as quais o fato de ser mulher 'naturalmente' as habilitaria. 
[...] eu mudo de função sabe, eles ficam mudando, passei um ano e meio só na calibração de banana. Só fazia calibrar a banana tipo que ela tava grossa ou fina pra ela ir pra exportação porque pra exportação tem um calibre certo [...] aí passei um ano e meio nisso, aí depois eu entrei de férias e quando voltei me mudaram pra seleção. Aí fiquei na seleção, tava com um ano na seleção e agora me tiraram que é fazendo os clusters da banana, que a banana é em palma e aí eu faço os 'clôcho' de quatro a oito [...] Eu pego a palma e boto em cima de uma banca, corto com a faca, faço bem direitinho, ajeito em cima a coroa, aí boto e lá na frente tem outras mulheres que botam numa bandeja, numa esteira que vai lá pros embaladores. (Gezabel, 52 anos).

Ao descrever as funções desempenhadas na empresa, Gezabel evidencia que todas as atividades por ela realizadas são anteriores à fase de embalagem das frutas. São funções como calibração, seleção e divisão das palmas da banana que seguem para o bandejamento, também feito por mulheres, para depois seguir para a embalagem, função exercida pelos homens: "é só homem que faz [...] porque é cansativo e mulher nenhuma aguenta a função do embalamento, só o homem". Assim, percebe-se uma divisão da rede de significados construída em torno do trabalho assumido pelos homens e pelas mulheres. A elas estão destinados os trabalhos associados à atenção e ao cuidado, e a eles destinam-se os trabalhos associados à força física, mas ambos compartilham de um ritmo de trabalho acelerado e são permanentemente pressionados pelas metas de produtividade. Marcondes et al. (2003) alertam que entre os atributos associados às mulheres, a 'calma' e a 'paciência' estão entre os mais valorizados, pois, embora os trabalhos designados a elas sejam compreendidos como 'leves', em geral, são marcados por esforços repetitivos, posturas inadequadas e ritmo acelerado, portanto, a paciência seria uma virtude imprescindível.

\section{A intensificação do ritmo do traba- lho e a expropriação do tempo das mulheres}

Verificou-se que a base salarial oferecida pelas empresas é basicamente a mesma e se limita ao salário mínimo. O que diferencia o valor da remuneração das trabalhadoras é a produção que excede as metas estabelecidas para a jornada de trabalho que é de 44 horas semanais. No entanto, as metas de produção já são extremamente altas, ou seja, para conseguirem ganhar a mais por produção, as mulheres precisam acelerar intensamente o ritmo de trabalho. O pagamento por produção também aprofunda uma das dimensões da desigualdade de gênero que é a disparidade da remuneração recebida por homens e mulheres. Embora o salário base de homens e mulheres seja o mesmo, as funções exercidas por eles são vistas como mais pesadas e até mesmo como mais importantes, por isso, o valor que eles recebem pela produção é pelo menos o dobro daquele recebido pelas mulheres.

O homem ganha mais porque eles trabalham em cima da produção de caixa, por exemplo, se nós for tudo embalador e se eu fizer mais caixas que você eu ganho mais. É em cima da produção porque nós já ganha em cima da produção também por causa deles, se eles ganhar $R \$ 20$ reais aí nós ganha $R \$ 10$ [...] Por exemplo, se nós passar 4 mil caixas, que é muito, tem embalador lá de fazer 700 ou 800 caixas, aí se eles ganhar $R \$ 30$ de produção aí nós ganha $R \$ 20, R \$ 15$. (Gezabel, 52 anos).

O volume da produção é mensurado pelo número de caixas embaladas, serviço realizado pelos homens, mas que depende do trabalho realizado pelas mulheres nas etapas anteriores, ou seja, quanto mais rápido as mulheres trabalharem, mais caixas os homens conseguirão empacotar. A pressão para atingir e superar as metas repercute no prolongamento das jornadas de trabalho. Ambas as empresas pesquisadas trabalham 
com metas de produção, embora apenas uma pague as mulheres por produtividade. Nesse sistema, as mulheres só encerram sua jornada de trabalho quando as metas são plenamente cumpridas, mesmo que isso implique horas extras. Dessa maneira, o estabelecimento de 44 horas semanais para a jornada de trabalho não é real, pois as trabalhadoras apontaram que "só tem hora pra entrar, pra sair não", em uma clara violação à legislação trabalhista, que não permite a obrigatoriedade de horas extras e nem sua realização por tempo indeterminado.

Quando a gente assinou o contrato, vinha dizendo que a gente é obrigado a fazer duas horas depois das horas trabalhadas. Aí então, a gente sabia que não era obrigada a ficar até $10 \mathrm{~h}$ da noite. Mas se a gente não ficasse até $10 \mathrm{~h}$ da noite, a gente não ia ter a produção. Era arriscado, às vezes eles ameaçavam dar uma suspensão no outro dia e a gente ficava, trabalhava pra ver se recebia um dinheiro melhor no final do mês. (Yasmin, 31 anos).

Tinha que fazer. A gente era obrigada a fazer. Ou você fazia ou você vinha pra casa. Levava 2, 3 dias de suspensão. Reduzia no salário que era pra gente aprender. Como a gente precisava do emprego... A gente tinha um fiscal que era muito carrasco. (Jaqueline, 37 anos).

Por receberem baixos salários, as mulheres se submetem à aceleração do ritmo de trabalho e ao cumprimento de horas extras irregulares, pois é o excedente das metas de produção que garante um complemento salarial. Todas as trabalhadoras entrevistadas relataram a excessiva carga horária que enfrentam diariamente "Entrava $5 h d a$ manhã, saia $12 \mathrm{~h}$ da noite! Já teve dia que eu cheguei em casa 9 h do outro dia" (Jaqueline, 37 anos). As entrevistas revelam o aumento de tensões provocadas pelo acúmulo de trabalho que limita o tempo para a realização de outras atividades básicas como o sono e o descanso.
Quando eu vejo que tem muita luta mesmo, eu acordo 5 h30 pra adiantar o serviço da casa, sabe? [...] Que não tem quem faça pra mim. A minha mãe já fica com meus filhos... E o dinheiro é pouco, né? Pra pagar alguém. Aí eu faço. O dia que eu tenho tempo pra descansar um pouquinho, e ainda é um pouquinho, é dia de domingo, assim, depois de meio-dia que eu já termino de fazer as coisa tudo, é que eu me deito um pedacinho. Mas não falta serviço. (Paloma, 26 anos).

As trabalhadoras vão criando estratégias para conseguirem cuidar dos filhos, que vão da dependência da solidariedade de terceiros, sobretudo familiares e vizinhos, a adaptações na rotina de trabalho. É comum que algumas mulheres aceitem trabalhos sazonais nas empresas do agronegócio, intensamente precarizados, visando alternar períodos de maior atenção aos filhos. No entanto, como salientam Arreal e López (2014), essa contínua adaptação da vida ao trabalho doméstico acaba reforçando as desigualdades de gênero e camuflando a ausência de equipamentos públicos de assistência às trabalhadoras e às crianças. Infelizmente, as políticas públicas não são construídas considerando a conciliação entre trabalho produtivo e reprodutivo em sua relação com a desigualdade da organização do tempo social de homens e mulheres. Disso resulta uma tensão constante sobre as mulheres em relação aos cuidados com a vida familiar, sobretudo com os filhos. Percebe-se entre as entrevistadas que a dificuldade de acompanhar o cotidiano dos filhos é produtora de angústia e sofrimento que não são mensuráveis, mas que são significativos para que se possa compreender que as mudanças referentes ao tempo suprimido dessas mulheres são potencialmente geradoras de conflitos internos e adoecimento.

A maior parte do tempo da gente é dentro da empresa, né? Então a gente tenta fazer o básico. O que dá pra fazer. Mas tudo? Não tem como a gente dar de conta. Quando a gente tem alguém 
da família perto, tudo bem. Mas quando a gente não tem, dificulta! Porque a gente não tem como. Como é que eu vou chegar em casa por exemplo, 8h, 9h, 10h da noite e arrumar a casa e fazer tudo? Não tem! Essa questão da lição de casa, da agenda do menino, não tem! Não tem como! [...] aí então, é difícil eu acompanhar eles, reunião na escola era difícil eu ir [...] eu pedia muita ajuda dos amigos, dos vizinhos pra olhar eles, pra me dizer o que tava se passando, o que tava acontecendo porque eu não tinha como ficar sabendo por que eu saía de manhã e chegava à noite. (Yasmin, 31 anos).

Observa-se que o avanço do agronegócio no campo interfere na dinâmica e nos ritmos de vida das populações camponesas afetando, principalmente, as mulheres. $\mathrm{O}$ aumento da participação delas na esfera produtiva não reduz a sua participação na esfera reprodutiva, ao contrário, pode-se dizer que as mudanças ocasionadas pelo redimensionamento do tempo promovem uma articulação perversa entre trabalho produtivo e reprodutivo que aprofunda a desigualdade entre homens e mulheres.

\section{Vulnerabilizações e riscos à saúde das trabalhadoras do agronegócio}

Em relação às exigências das atividades de trabalho destinadas às mulheres, problematizou-se que, mesmo que a divisão sexual conduza a uma compreensão de que a elas se destinam os trabalhos mais 'leves', ou seja, aqueles que não implicam carregar peso, riscos como a repetição dos movimentos, o ritmo intenso, as posturas inadequadas podem ser fatores de adoecimento, além dos acidentes. Para Marcondes et al. (2003), o peso do trabalho considerado leve precisa ser visibilizado e isso só acontece caso se considere não só o peso ou o esforço físico investido na tarefa desempenhada. Para Marcondes et al. (2003), é importante considerar que os postos de trabalho assumidos pelas mulheres muitas vezes exigem esforços que passam despercebidos, como posturas desfavoráveis, repetição exaustiva de movimentos e impossibilidade de se movimentar livremente, que podem implicar sofrimento físico e mental.

Na cadeia produtiva analisada, encontrou-se uma conjunção desses fatores, pois o trabalho na packing house é desenvolvido em uma cadência acelerada, de modo que as mulheres têm poucas possibilidades de sair de seus postos de trabalho ao longo da jornada. Elas trabalham em pé durante todo o dia e, além dos 60 minutos de almoço, só podem fazer uma única pausa de 15 minutos por turno. Todas as entrevistadas reclamaram do cansaço resultante de longos períodos sem poder sentar. Algumas citaram as estratégias que usam quando não suportam mais o cansaço

A sorte é que tem a impressora, aí tem um bicho de ferro que fecha ela assim, que a gente bota assim de pé e se senta. É, lá ninguém trabalha sentado não. Só quem trabalha no escritório mesmo. Eu me sento nesse bicho [risos]. Enquanto o gerente geral tá, eu fico em pé, mas ele sai, eu me sento. (Lia, 27 anos).

No entanto, Lia só consegue utilizar essa estratégia porque a função que exerce na empresa de melão, registrando o carregamento de contêineres, exige que ela se movimente por um espaço maior. Entretanto, para as mulheres que trabalham em funções como a seleção de frutas, a possibilidade de criar esse tipo de estratégia é quase nula uma vez que ficam confinadas em um longo e estreito corredor que limita os movimentos (figura 3). 
Figura 3 . Condições de trabalho no setor packing house da empresa $X$

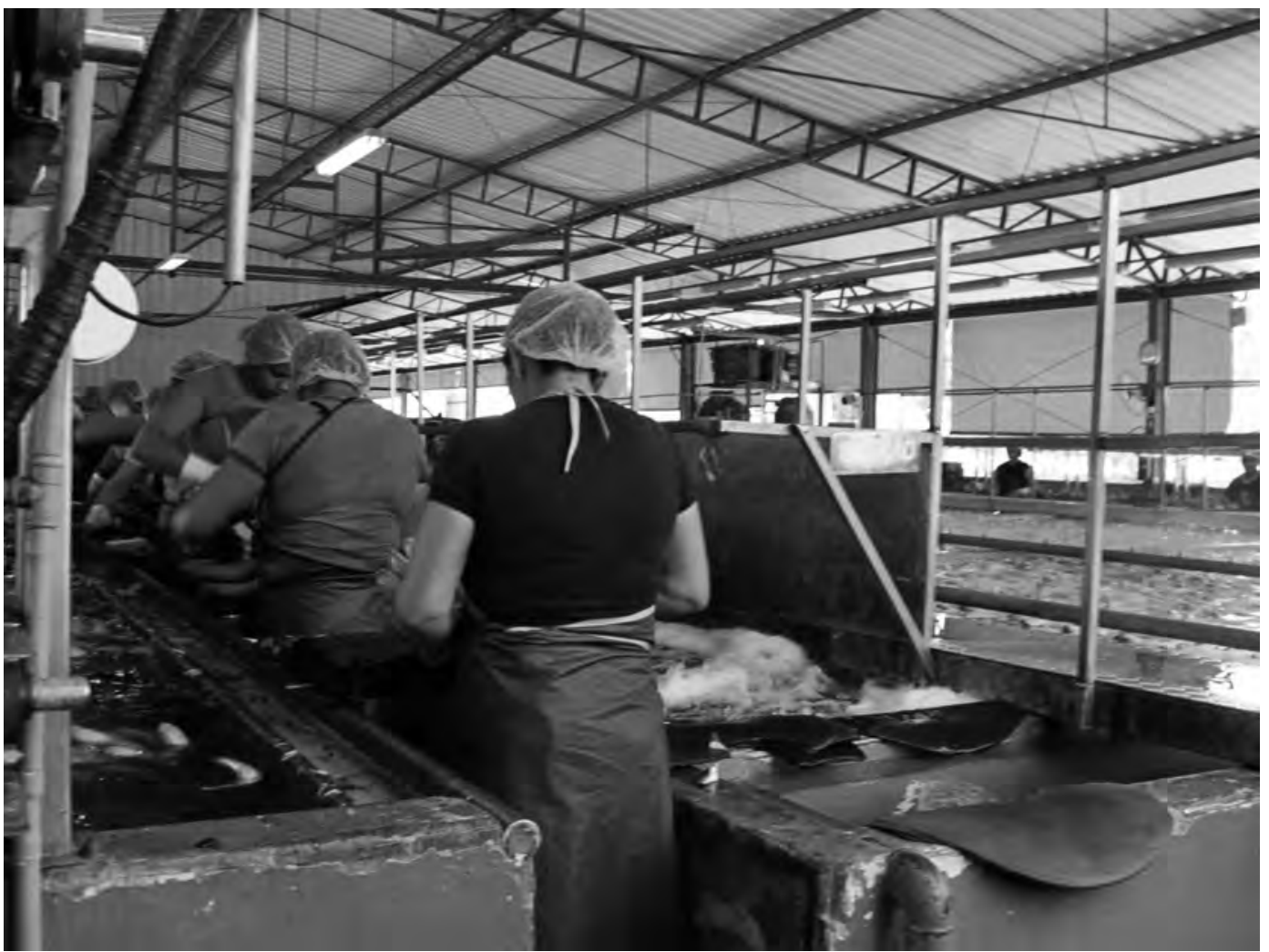

Fonte: Acervo da pesquisa

As condições de trabalho descritas pelas mulheres são precárias e as expõem a uma série de riscos ocupacionais. Todas as entrevistadas apontaram que, além de passarem o dia em pé, os movimentos realizados e a posição em que trabalham acarretam muitas dores nos braços e na coluna. Paloma, uma jovem de 26 anos que trabalha na empresa $Y$, reclama das dores que sente nas costas, principalmente quando precisa acelerar o ritmo da produção, e reflete sobre a possibilidade de ter problemas de saúde futuros ocasionados pelo trabalho.

Agora eu não sei [se o trabalho prejudica a saúde], talvez não, mas com o passar do tempo... assim... porque é uma função em pé, sabe? Assim, cabeça baixa, na vista assim é fácil, mas, Ave Maria, só falto morrer de dor nas costa.
Assim, quando aumenta, sabe? Aquele tanto de caixa você tem que ser mais ligeiro, né? [...] Então força o corpo da gente. E eu sinto muita dor na coluna, sabe? (Paloma, 26 anos).

As queixas de LER/Dort (Lesões por Esforços Repetitivos/Doenças Osteomusculares Relacionados ao Trabalho) se sobressaíram nos depoimentos das entrevistadas, e todas foram capazes de citar com facilidade colegas afastadas do trabalho por queixas dessa natureza.

Sinto muita dor nos braços, aí agora eu tô com hérnia de disco na coluna aqui embaixo, tô com duas hérnias de disco nesse osso do pescoço, com artrite, artrose, outras coisas. Na empresa que eu trabalho não sou só eu que tô assim. (Jaqueline, 37 anos). 
De acordo com Arreal e López (2014), as mulheres representam o grupo mais atingido por doenças e lesões osteomusculares relacionadas com o esforço repetitivo no trabalho. Além do adoecimento, as mulheres sofrem com a desconfiança sobre as queixas que apresentam, conforme relata Jaqueline que, no período da pesquisa, estava afastada do trabalho:

Tem noite de não dormir com dor, e a pessoa chegar pra você e dizer que você não tem doença, que você tá fingindo. Isso dói. Porque ninguém tá sabendo do meu sofrimento. E é muito ruim você viver em casa sem poder fazer nada. Minha casa suja, porque não tenho disposição de tanta dor que tenho nos braços. Na maioria das vezes meu marido chega e não tem nem comer dentro de casa. Isso é vida? Vou dizer que me sinto bem desse jeito? Eu sou nova, mas me achar nessa condição que eu me encontro hoje?! (Jaqueline, 37 anos).

De acordo com Ramos et al. (2010), o afastamento do trabalho gera sentimentos de impotência que, no caso de LER/Dort, é agravado por gerar dependência de outras pessoas para a realização de atividades simples, e causa sofrimento às mulheres. Esse sofrimento é demonstrado por Yasmin que, no período da pesquisa, havia sido demitida da empresa, após sucessivos afastamentos, e buscava na justiça uma indenização:

Tem dias que eu choro aqui dentro de casa porque se eu lavar uma roupa, no outro dia, eu amanheço doente. Meus filhos arrumam a casa e, pra não dizer que não estou fazendo nada dentro de casa, eu lavo roupa com esforço e o almoço, o resto é eles quem faz. Então, eu vou lavar roupa, mas é todo tempo baixando meus braços porque eu não aguento ficar com meus braços levantados e pra estender [a roupa] é outro esforço [...] estou prejudicada e tem dias aqui que eu choro, eu me estresso, porque você vê suas coisas por fazer e não ter a capacidade de fazer! Então isso é uma coisa assim que mexe comigo. Eu fico muito triste com isso. (Yasmin, 31 anos).
Prazeres e Navarro (2011), ao estudarem o trabalho das mulheres na indústria calçadista, observaram que os efeitos do adoecimento relacionado com o trabalho não se limitam ao sofrimento do corpo, pois coexistiam com sofrimentos de ordem psíquica. Essa mesma realidade foi verificada ao ouvir os relatos de depressão, ansiedade, angústia extrema e perda do sono das entrevistadas.

Amanhã faz 15 dias que eu não consigo dormir que preste. Não tenho vergonha de dizer. Toda noite eu durmo com dor, não durmo e nem deixo meu marido dormir. Ele tá aí pra não dizer que é minha mentira. Os meus quarto é tudo roxo de tomar injeção, tem hora que eu não sei o que fazer. (Jaqueline, 37 anos).

Além das doenças decorrentes dos esforços repetitivos e ritmo intenso de trabalho, as entrevistadas evidenciaram os problemas de saúde decorrentes do ambiente extremamente quente e úmido em que trabalham.

[...] dá inflamação, porque as inflamação é devido aquelas roupas, porque a gente vive de calça comprida, veste aqueles avental quente, a posição também, né? Aí só dava mais inflamação no pé da barriga por causa do trabalho. (Amanda, 36 anos).

No caso da empresa produtora de banana, os problemas se gravam pelo fato de que as mulheres ficam o dia todo em contato direto com a água dos tanques. De acordo com os relatos, as luvas que são fornecidas pelas empresas não protegem suficientemente, e são comuns irritações na pele e perda das unhas.

Por causa de um produto que eles colocavam na água que eu não sei dizer o nome, a mão da gente ficava coçando e inchada. E não era só uma [mulher] não, eram muitas [...] Porque não tem como a gente trabalhar e não molhar as mãos. Sempre a gente molha, porque além das luvas serem pequenas, a gente não consegue ficar com as luvas grandes por causa do calor. (Jaqueline, 37 anos). 
As trabalhadoras relataram que a água dos tanques recebe tratamento com diversos produtos químicos utilizados para limpar o látex da banana. No entanto, nenhuma delas soube responder quais seriam esses produtos, isso demonstra que a falta de informação limita a possibilidade de as mulheres dimensionarem os riscos aos quais estão expostas. Elas trabalham sem uniforme utilizando roupas próprias, e a empresa fornece apenas luvas, toucas e um avental; materiais que foram descritos como insuficientes para proteção.

Ali não tem farda, não. É a roupa comum da gente e aquele avental amarrado na cintura que eles dão. Geralmente, quase sempre, os aventais eram rasgados e a gente se molhava todinha. Teve mulher lá que teve coceira por baixo porque aquela água dos tanques é tudo com produto [...] Tem dia que eles botam tão forte, mulher... que você... que a gente não trabalha com máscara ali, né? Você sente aquele bafo, né? (Amanda, 36 anos).
Um fator agravante das condições insalubres é a convivência com produtos químicos desconhecidos e agrotóxicos. A modernização agrícola tem como uma de suas características fundamentais a utilização intensiva de produtos químicos como fertilizantes, fungicidas, herbicidas, acaricidas, entre outros. Esses produtos são utilizados não apenas nos campos, mas também na fase final de tratamento das frutas. Antes de seguir para exportação, elas recebem novos 'banhos' de veneno, o que é realizado de forma muito próxima às mulheres e, em alguns casos, são aplicados por elas mesmas. As entrevistadas reclamaram de sentir o odor dos produtos e disseram que, dependendo da atividade na qual são alocadas, podem sentir os efeitos da exposição no corpo como irritações na garganta, nos olhos e no sistema respiratório. Daysiele evidencia que a atividade que mais a incomoda é a pesagem das frutas, pois a tarefa é realizada na sequência da aspersão de fungicidas sobre as bananas, como nota-se nas imagens (figuras 4 e 5).

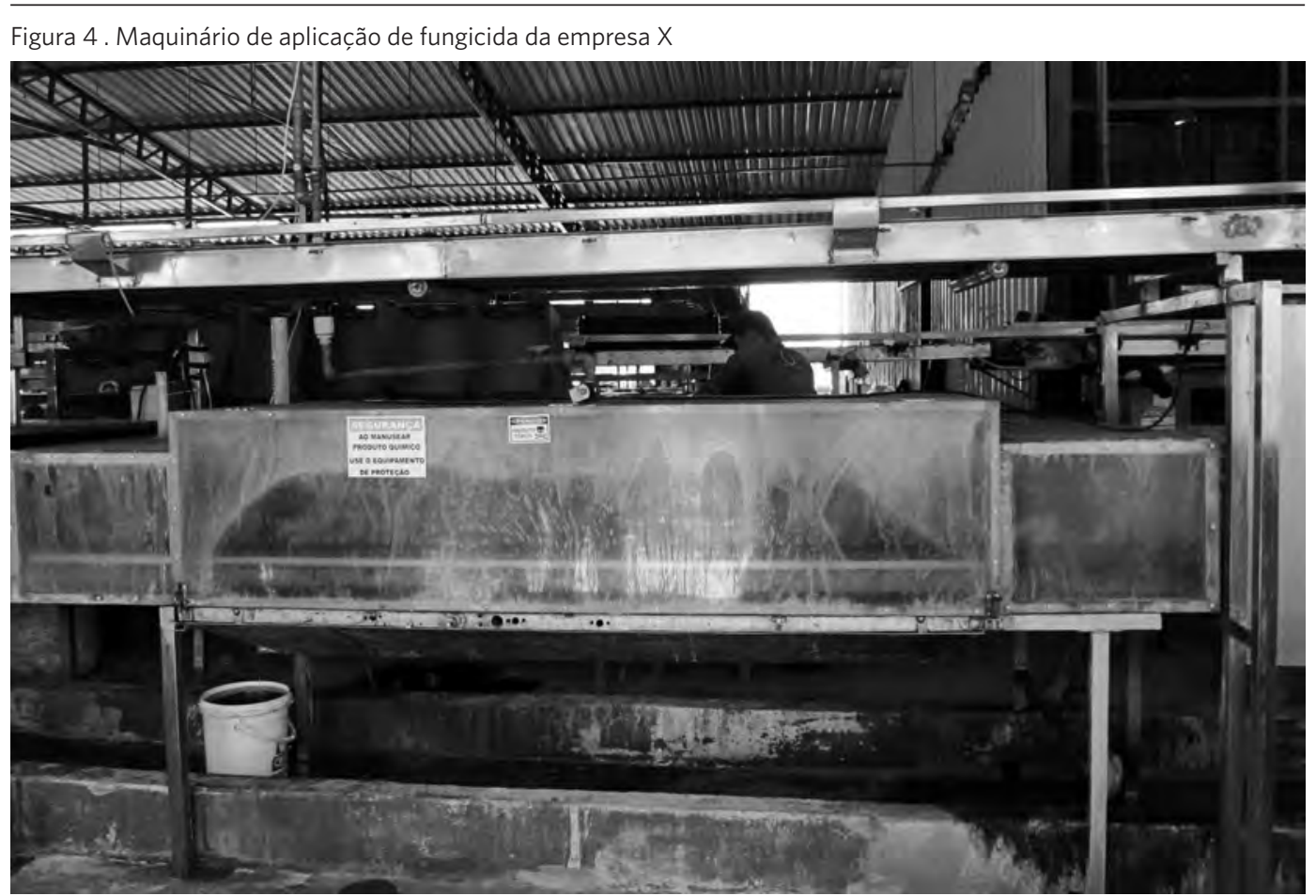

Fonte: Acervo da pesquisa. 
Figura 5. Posto de trabalho imediatamente após aplicação de fungicida

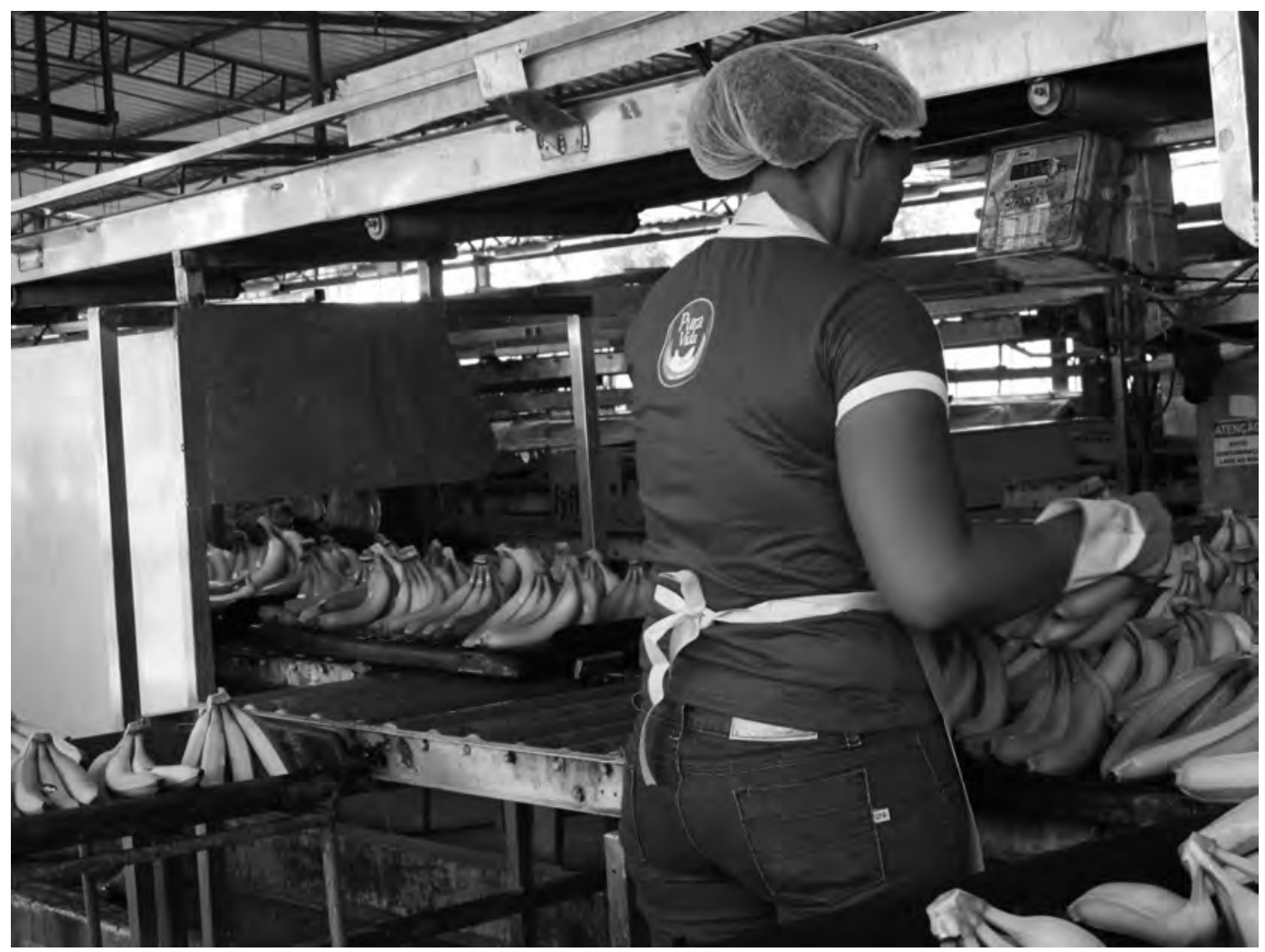

Fonte: Acervo da pesquisa.

Quando eu tô com 'estalecido', a maior parte é porque eu tô no peso. No peso recebe muito o expurgo, o veneno, que bota na banana mesmo. Antes do peso pra lá tem aquela esteira [...] tem o expurgo, aí o vento que dá vem pra gente. Ali é o veneno. Tem dia que chega eu fico rouca. (Daysiele, 26 anos).

O que Daysiele classifica como 'estalecido' refere-se a sintomas das vias respiratórias, apontados de forma recorrente pelas mulheres, que podem estar relacionados com os efeitos irritantes dos agrotóxicos que, no cotidiano do trabalho, tendem a ser pouco visibilizados ou percebidos como 'fazendo parte' da rotina. De acordo com Britto (1999), a relação entre o trabalho e a saúde é muitas vezes expressa pelas mulheres de forma inespecífica. Ao estudar o trabalho das mulheres em indústrias farmacêuticas e cosméticas, a autora ressalta que as alergias e irritações são as patologias mais mencionadas, sobretudo as relacionadas com o sistema respiratório como rinites e asmas, e salienta a dificuldade de identificação das substâncias às quais estão expostas devido à grande variedade de produtos químicos utilizados. $\mathrm{O}$ mesmo se aplica às empresas agrícolas aqui analisadas, e, assim como a autora sugere, acredita-se que os dados recolhidos pela pesquisa sobre os efeitos do trabalho no corpo das mulheres precisam ser analisados qualitativamente, pois

as queixas inespecíficas, bem como certas percepções relativas ao ambiente (odores, calor, etc), devem ser analisadas como 'sinais de alerta'[...]. (BRITTO, 1999, P. 152).

Aqueles venenos que passam na banana, ali é muito prejudicial. A pessoa ficar ali perto. Dá um 
bocado de coisa, alergia, dá escorrimento. Como uma vez já teve uma colega minha que teve escorrimento de sangue pelo nariz porque não usava os EPI direito. Mesmo eles dizendo que tem que usar, né? Porque fica ali perto dos produtos. Pessoas que no tanque ali, lavando banana, como eu faço, quando tá forte pessoas fica passando mal. [...] Dava cansaço, falta de respiração. Porque o bicho é forte mesmo. Acho que eles botam [veneno] demais! (Amanda, 36 anos).

Embora irritações, processos alérgicos, sintomas de intoxicações e dores nas articulações e nos músculos sejam frequentemente relatados, as mulheres denunciam que esses problemas são minimizados pelo setor médico das empresas. Elas afirmam que só recorrem ao ambulatório quando não conseguem suportar as dores que sentem, pois o procedimento geral se reduz a medidas paliativas para bloquear os sintomas de forma que elas voltem imediatamente aos postos de trabalho. Além disso, foi amplamente relatado o fato de as empresas pressionarem os profissionais de saúde para que eles não dispensem as trabalhadoras e evitem emitir e também aceitar atestados médicos, em clara violação das leis que regulamentam as funções do setor de atendimento médico das empresas.

Muitas pessoas sofrem de alergia, às vezes as unhas da gente caem e as luvas são mais ou menos aqui assim, né? [indicando que são curtas] $E$ às vezes, quando você desce a mão pra pegar a banana entra [água] e começa a cair as unhas. [...] Só de uma vez que minhas unhas sempre foi grande, mas eu sempre usava as luvas, né? Aí arregaçou a unha, subiu, sabe. Aí eu fui pro hospital pra arrancar e o médico só me deu dois dias. Aí eu fui ao Dr. X [médico da empresa] e ele disse que dava pra trabalhar, enfaixou e mandou eu ir trabalhar. Mas aí começou a inchar, inchar, inchar. Aíeu vim para o Dr. Y [médico do posto de saúde] que me deu cinco dias. Aí eles [a empresa] acharam ruim. O médico daqui [da empresa] só me deu dois dias. Me deu pela hora da morte porque eles sabe que a empresa é cruel com todos os médicos, viu? Se der atestado. (Amanda, 36 anos).
Observa-se que, além dos profissionais de saúde das empresas serem pressionados a fazer com que as mulheres retornem rapidamente aos postos de trabalho, elas próprias são desestimuladas a procurar atendimento fora da empresa.

[...] eu passava muito tempo sem ir ao médico porque eu não queria colocar um atestado, nem faltar. Então quando eu procurei a fazer exames e me cuidar, eu descobri muita doença. [...] Quando eu vim fazer exame, aí eu vim descobrir foi uma coisa atrás da outra. Eu passei muito tempo só me dedicando ao trabalho, porque a gente, quando a gente trabalha numa empresa dessa a gente se dedica mais ao trabalho. Quando a gente sai de casa, só tem hora de sair de casa, não tinha hora para chegar. (Yasmin, 31 anos).

As limitações que as mulheres encontram para acessar o sistema público de saúde não decorrem apenas da dupla jornada de trabalho, pois resultam também da pressão que sofrem das empresas para não exercerem o direito de buscar atendimento médico, conforme indica Amanda (36 anos):

Eu passei dois anos sem fazer prevenção [de câncer ginecológico]. Porque quando eu pedia pra mim sair mais cedo, que eu marcava aqui no Tomé, eles [os encarregados] não queriam liberar.

Com a pesada carga horária demandada, uma das alternativas que elas possuem é faltar ao trabalho, visto que liberações quase nunca ocorrem.

Se a gente fosse dizer assim: eu vou fazer um exame, eu preciso fazer. Eles não iam dizer: vá! Não, não é? [...] até que chegou um dia que eu conversei com o pessoal lá no escritório. Eu disse que era pra mim fazer um exame, eu tive que dizer qual era o exame que eu ia fazer ao fiscal, porque ele não queria que eu faltasse. (Yasmin, 31 anos). 
A trabalhadora relata que evitava buscar atendimento, pois precisaria entregar atestado "Porque lá nesse termo de atestado e falta eles são um pouco rigoroso. Porque não é bom pra gente nem pra empresa a gente tá colocando [atestado]" (Yasmin, 31 anos). Uma das estratégias utilizadas pela lógica produtivista para que as próprias mulheres incorporem que também não é bom para elas procurar os serviços médicos é o alcance das metas de produtividade. Em caso de falta, mesmo com comprovação de atestado médico, as mulheres são prejudicadas, pois não recebem pela produção daquele tempo em que estiveram fora.

No que se refere à atenção a saúde das trabalhadoras, as entrevistadas indicaram que há negligência e violações de direitos relativas ao atendimento médico diante de casos de acidentes de trabalho, como fica explícito no relato de Amanda que sofreu um acidente durante a jornada de trabalho na empresa $\mathrm{X}$ :

Tem aquelas barras de ferro, a gente passa por cima. Aí a mulher lava aquilo com ácido e o ácido vai consumindo o ferro. A gente fica pisando de lá pra cá, correndo atrás de bandeja e aí quebrou uma [barra de ferro] e eu fiquei dentro do buraco com o joelho enganchado. A bolacha do joelho veio pra cá [se deslocou]. Aí ninguém me tirou lá de dentro. Quem me tirou foi uma senhora que trabalhava do meu lado. Olhe, eles [os supervisores] acharam que era frescura. Eu saí chorando lá pra traz do vestiário e lá eu fiquei até vim embora. Eles achando que era frescura. O joelho inchou, ficou roxo, a coxa inchou e os pés. Eu cheguei aqui [em casa] só com uma perna pulando, chorando com dor. Aí fiquei esperando que eles viessem porque o certo era eles virem aqui, me levarem para o hospital e prestarem assistência, né? O que fizeram foi no dia seguinte o Dr. [médico da empresa] tirou quase uma bacia de sangue do joelho, pegou uma talisca, engessou e pronto. Não bateu um raio-x, não fez nada. Me mandou passar 15 dias em casa. Quando voltei com o joelho que passou 15 dias duro, ele [o médico] dobrou a força e mandou eu ir trabalhar. Aí foi que começou a inchar. Eu não fui [trabalhar].
Aí começou a polêmica. Passei mais 2 dias em casa, com o joelho inflamado, mas voltei a trabalhar com a perna dura assim mesmo [...] Eles acharam que era frescura. Não fizeram mais exames e nada. (Amanda, 36 anos).

Outra violação de direito que apareceu nas falas das trabalhadoras diz respeito à negligência com a saúde das trabalhadoras grávidas. Elas relatam que dificilmente são mudadas de função durante o período de gravidez, mesmo quando desempenham atividades que as expõem a riscos e nas quais cumprem a jornada de trabalho em pé entre os tanques da packing house, como descreve Daysiele:

Até os 6 meses eu fiquei na seleção, aí ficava ruim porque o tanque batia na minha barriga e eu ia reclamar e eles diziam que gravidez não é doença. Mas, geralmente, machucava a barriga da gente. Os fiscais que diziam que gravidez não é doença [...] senti muita dor no pé da barriga, aí eu fui reclamar e não gostaram, aí deixaram eu lá. (Daysiele, 26 anos).

Diante de todos os relatos feitos pelas trabalhadoras, pode-se afirmar que os ambientes de trabalho em que essas mulheres atuam oferecem riscos e as vulnerabilizam provocando adoecimento e sofrimento. Percebe-se que direitos estão sendo violados e que as necessidades de saúde das mulheres estão sendo invisibilizadas e negligenciadas no contexto da reestruturação produtiva ocasionada pela expansão da modernização agrícola na Chapada do Apodi (CE).

\section{Considerações finais}

Observou-se que os processos de trabalho nas empresas de fruticultura irrigada da Chapada do Apodi, Ceará, incorrem numa combinação de formas de dominação do trabalho realizado pelas mulheres. Este artigo buscou compreender de que maneira a saúde 
das trabalhadoras tem sido afetada pela organização do trabalho na cadeia produtiva do agronegócio naquela região, e, entre os aspectos analisados, encontraram-se situações de vulnerabilização provocadas pela divisão sexual e pela subvalorização do trabalho das mulheres. Constatou-se que as trabalhadoras vivenciam um cotidiano marcado pela intensificação e pela precarização de suas condições de trabalho que resultam em adoecimento e desgaste físico e mental.

A reconstituição do processo de trabalho das mulheres empregadas no agronegócio levou a refletir que a organização e a divisão sexual do trabalho, o ritmo e a cadencia acelerada, a violação de direitos trabalhistas, a instabilidade dos empregos, os baixos salários e os ganhos por produtividade precisam ser considerados como fatores relevantes para analisar os impactos do trabalho sobre a saúde das mulheres

\section{Referências}

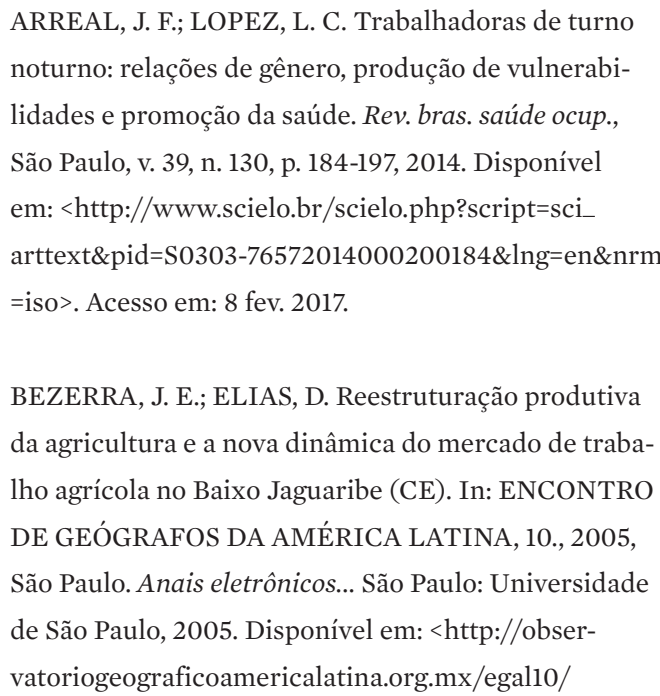

para além dos fatores de risco do trabalho, pois estes seriam insuficientes para compreender as causas do sofrimento e adoecimento das trabalhadoras. Por fim, atentou-se que é preciso ampliar as investigações que articulem as reflexões entre as categorias de gênero, saúde e trabalho com a de ambiente. Embora não tenha sido o objeto deste artigo, ao longo da pesquisa, verificou-se que o avanço do agronegócio no campo ocasiona transformações territoriais que interferem sobre a saúde das mulheres ao desorganizar os modos de vida ali existentes e ampliar as desigualdades de gênero.

\section{Colaboradores}

As autoras declaram que participaram igualmente da concepção, análise e a interpretação dos dados do artigo.
Geografiasocioeconomica/Geografiaagricola/07.pdf > . Acesso em: 15 ago. 2016.

BRITTO, J. C. Saúde, trabalho e modos sexuados de viver. Rio de Janeiro: Fiocruz, 1999.

CASTRO, F. S. C.; BRAGA, L. Q. V. Diversidades do trabalho: da monocultura da banana à apicultura agroecológica. In: RIGOTTO, R. M. (Org.). Agrotóxicos, trabalho e saúde: vulnerabilidade e resistência no contexto da modernização agrícola no Baixo Jaguaribe/CE.

Fortaleza: UFC, 2011. p. 361-390.

FERNANDES, F. M. B.; MOREIRA, M. R.

Methodological considerations on the possibilities 
of application of the participant observation technique in Public Health. Physis, Rio de Janeiro, v. 23, n. 2, p. 511-529, 2013. Disponível em: <http://www. scielo.br/scielo.php?script=sci_arttext\&pid=S0103$-73312013000200010 \& \operatorname{lng}=$ pt\&nrm=iso $>$. Acessos em: 8 fev. 2017.

HARVEY, D. Condição pós-moderna: uma pesquisa sobre as origens da mudança cultural. São Paulo: Edições Loyola, 1992.

IÑIGUEZ, L. A linguagem nas ciências sociais: fundamentos, conceitos e modelos. In: Manual de análise do discurso em ciências sociais. Petrópolis: Vozes, 2004. p. 50-104.

LASTARRIA-CORNHIE, S. Feminización de la agricultura en América Latina y África Tendencias y fuerzas impulsoras. Debates y temas rurales, Santiago do Chile, n. 11, p. 1-25, 2008.

MARCONDES, W. B. et al. O peso do trabalho "leve" feminino à saúde. São Paulo Perspec., São Paulo, v. 17, n. 2, p. 91-101, 2003. Disponível em: <http://www. scielo.br/scielo.php?script=sci_arttext\&pid=S0102$-88392003000200010 \& \operatorname{lng}=\mathrm{en} \& \mathrm{nrm}=\mathrm{iso}>$. Acesso em: 8 fev. 2017.

MINAYO, M. C. S. O desafio do conhecimento: pesquisa qualitativa em saúde. 13. ed., São Paulo: Hucitec, 2013.

\section{PIGNATI, A. W.; MACIEL, R. H.; RIGOTTO, R. M.} Saúde do Trabalhador. In: ROUQUAYROL, M. Z.; GURGEL, M. (Org.). Epidemiologia Et Saúde. 7. ed. Rio de Janeiro: Medbook, 2013. p. 355-381.

PORTO, M. F. Saúde, ambiente e o primado do interesse público. Saúde em Debate, Rio de Janeiro, v. 36, n. esp., p. 36-45, 2012.

\section{PORTO, M. F. S.; ROCHA, D. F.; FINAMORE, R.} Saúde coletiva, território e conflitos ambientais: bases para um enfoque socioambiental crítico.
Ciência \& Saúde Coletiva, Rio de Janeiro, v. 19, n. 10, p. 4071-4080, 2014. Disponível em: <http://www. scielo.br/scielo.php?script=sci_arttext\&pid=S1413$-81232014001004071 \& \operatorname{lng}=e n \& n r m=$ iso $>$. Acesso em: 9 nov. 2016.

PRAZERES, T. J.; NAVARRO, V.L. Na costura do sapato, o desmanche das operárias: estudo das condições de trabalho e saúde das pespontadeiras da indústria de calçados de Franca, São Paulo, Brasil. Cad. Saúde Pública, Rio de Janeiro, v. 27, n. 10, p. 1930-1938, 2011. Disponível em: <http://www.scielo.br/scielo. php?script=sci_arttext\&pid=S0102-311X201100100000 6\&lng=en\&nrm=iso>. Acesso em: 8 fev. 2017.

RAMOS, M. Z. et al. Trabalho, adoecimento e histórias de vida em trabalhadoras da indústria calçadista. Estud. psicol. (Natal), Natal, v. 15, n. 2, p. 207-212, 2010. Disponível em: <http://www.scielo.br/scielo. php?script=sci_arttext\&pid=S1413-294X201000020001 0\&lng=en\&nrm=iso>. Acesso em: 12 nov. 2016.

RIGOTTO, M. R. et al. Saúde do Trabalhador e Questão Ambiental. In: NAVARRO, V. L.; LOURENÇO, E. A. S. (Org.). O avesso do trabalho III: saúde do trabalhador e questões contemporâneas. São Paulo: Outras expressões, 2013. p. 143-164.

SOARES, A. Se eu pudesse não ser caixa de supermercado... Estudos Feministas, Rio de Janeiro, v. 5, n.1, p. 82-102, jan./jun. 1997.

THOMAZ JÚNIOR, A. Qualificação do trabalho: adestramento ou liberdade? Revista Pegada, v. 1, n. 1, 2000. Disponível em: <http://revista.fct.unesp.br/index. php/ pegada/article/view/764/785>. Acesso em: 17 maio 2017.

Recebido para publicação em agosto de 2016 Versão final em fevereiro de 2017 Conflito de interesses: inexistente Suporte financeiro: pesquisa realizada com apoio da Chamada $\mathrm{MCTI} / \mathrm{CNPq} / \mathrm{SPM}-\mathrm{PR} / \mathrm{MDA}$ № 32/2012. Processo: 405207/2012-3 